\title{
Analyzing the Contribution of Community Change to Population Health Outcomes in an Adolescent Pregnancy Prevention Initiative
}

Adrienne Paine-Andrews, Jacqueline L. Fisher, Jannette Berkely Patton, Stephen B. Fawcett, Ella L. Williams, Rhonda K. Lewis, \& Kari Jo Harris

For manuscript correspondence and reprint requests, contact: Adrienne Paine-Andrews, Ph.D., Principal Investigator, 4082 Dole Center, University of Kansas, Lawrence, KS 66045, phone: 785-864-0533, fax: 785-864-5281, email: apa@ku.edu

Jacqueline L. Fisher, M.P.H., CHES, Associate Director and Principal Investigator, Work Group on Health Promotion \& Community Development, 4082 Dole Center, University of Kansas, Lawrence, KS 66045, phone: 785-864-0533, fax: 785-864-5281, email: jfisher@ukans.edu

Jannette Berkely Patton, M.A., Project Director, Social Norms Media Campaign, 36 Strong Hall, University of Kansas, Lawrence, KS 66045, phone: 785-864-5980, email: jbpatton@ku.edu

Stephen B. Fawcett, Ph.D., Director, Work Group on Health Promotion \& Community Development, 4082 Dole Center, University of Kansas, Lawrence, KS 66045, phone: 785-864-0533, fax: 785-864-5281, email: sfawcett@ku.edu

Ella L. Williams, M.Ed., is Project Director, City Vision Ministries, Kansas City, KS

Rhonda K. Lewis, Ph.D., Assistant Professor, Department of Psychology, Wichita State University, 1845

Fairmount, Wichita, KS 67208, (316) 978-3695, fax (316) 978-3086, email: rklewis@wsuhub.uc.twsu.edu

Kari Jo Harris, Ph.D., M.P.H. Research Assistant Professor, Department of Preventive Medicine, University of Kansas School of Medicine, 3901 Rainbow Blvd, Kansas City, KS 666160-7313, phone:

913-588-2747, fax: 913-588-2780, email: kharris2@kumc.edu

Key words: adolescent pregnancy, community change, health outcomes, prevention

Running head: Analyzing Change 
Analyzing the Contribution of Community Change to

Population Health Outcomes in an Adolescent Pregnancy Prevention Initiative 


\begin{abstract}
Few evaluations of community initiatives have established a link between intermediate outcomes, such as community or systems change, and more distant population-level health outcomes (e.g., estimated rates of employment or adolescent pregnancy). This paper describes an analysis of the contribution of community changes facilitated by a community health initiative to prevent adolescent pregnancy to the population-level outcome of birth rates for teens. We examine a hypothesis that this link might be expected when community changes are of greater amount, intensity, duration and exposure. The results showed reductions in birth rates in Target Area A where there was a greater concentration of community changes and a slight increase where there were far fewer changes. This report provides a method for describing empirically the contribution of environmental change to more distant population-level outcomes.
\end{abstract}




\section{Analyzing the Contribution of Community Change to \\ Population Health Outcomes in an Adolescent Pregnancy Prevention Initiative}

Community coalitions, partnerships or initiatives are a prominent strategy for promoting community health and development. They are composed of people with varied experiences from a variety of sectors of the community who come together to build on community strengths, identify community concerns, such as to prevent adolescent pregnancy or promote youth development, and develop solutions to them. ${ }^{1,2,3}$ To facilitate improvements in health outcomes, staff, partners and key volunteers associated with community initiatives implement a number of programs, policies and practices consistent with their mission (i.e., community change).

Few evaluations of community initiatives have established a link between intermediate outcomes, such as community or systems change, and more distant population-level outcomes (e.g., estimated rates of employment or adolescent pregnancy). ${ }^{4,5}$ This paper describes an analysis of the possible link between intermediate outcomes (i.e., community changes) facilitated by an initiative to prevent adolescent pregnancy) and improvements in population-level health outcomes (i.e., estimated pregnancy or birth rates). First, we describe the context and working hypothesis for understanding conditions under which intermediate and more distant population-level outcomes may be related. Second, the methodology for documenting community change and analyzing its possible contribution is described. Third, data on the distribution of intermediate outcomes along the dimensions of the working hypothesis are presented to examine a possible link between intermediate outcomes and more distant outcomes. Finally, we offer recommendations for research and practice based on this analysis.

\section{Context for Exploration}

The context for this exploration is a multi-site comprehensive school/community initiative for prevention of adolescent pregnancy in Kansas. ${ }^{6,7,8}$ The broad mission of the Initiative was to improve social and health status in the community, related to adolescent pregnancy, through long-term change in environmental factors and personal behavior. This Initiative involved a partnership with three different local community-based initiatives (Geary County, Franklin County, and the northeast area of Wichita), the funder (Kansas Health Foundation, whose mission is to improve the health of Kansans), and a support and evaluation team (including the University of Kansas Work Group on Health Promotion and Community 
Development and the model originator from the University of South Carolina). Kansas Health Foundation funded each initiative for four-years $(1993$ - 1997) as well as the team at the University of Kansas and the model originator, Dr. Murray Vincent, in South Carolina ${ }^{6}$ Together these partners worked to implement the School/Community model ${ }^{6-9}$ and provide support and evaluation for local efforts.

This paper focuses on an analysis of data from one site, the northeast area of Wichita. Two target areas (distinct neighborhoods and different zip codes) in northeast Wichita, the largest city in Kansas, comprised the Wichita site. Combined, the two target areas in Wichita had about 30,000 people (Wichita total population, about 300,000 according to 1990 Census). The 5-year birth rate for both target areas combined for females age 15 to 19 years was 141.9/1000 compared to less than 70/1000 for Kansas. A grassroots, non-profit community organization in Target Area A, known as the Wichita Metropolitan Family Preservation, Inc., served as the lead agency for the project.

\section{Exploring a Working Hypothesis About Dimensions of Contribution}

This analysis focused specifically on understanding the link between community change (i.e., new or modified programs, policies, and practices facilitated by and consistent with the mission of the initiative) and population-level health outcomes (i.e., birth rates) associated with adolescent pregnancy., ${ }^{2,5}$ Community change is a metric reflecting changing conditions in the environment that help support widespread behavior change to improve a particular health outcome. The working hypothesis proposes that improvements in population-level health outcomes might be expected when community changes are of greater: (a) amount (i.e., the number of community changes reported), (b) intensity (use of behavior change strategies beyond information and skills training, attention to risk/protective factors and model components), (c) duration (length of time the changes remain in place), and (d) exposure (i.e., delivery to/through relevant community sectors to reach target groups in a particular locale). We predict that the contribution of community change (an intermediate outcome) to reducing teen birth rates (a more distant population-level outcome) will be more significant when there is a sufficient number of programs, policies or practices that target salient risk and protective factors for adolescent pregnancy, use more intensive behavior change strategies, are in place long enough to have an impact, and are widely distributed throughout the entire target area. 


\section{Method}

Several dependent measures and corresponding measurement instruments were used in this analysis. Each is described briefly below and in more detail in other publications. ${ }^{7,10,11}$

Dependent Measures and Measurement Instruments

The primary dependent measure was community change - new or modified programs, policies and practices facilitated by the initiative and consistent with its mission. ${ }^{10,11}$ The term community change was chosen to reflect changes in the usual ways of "doing business" in a community. Community changes include activities and services (in the form of new or modified programs) but go beyond service provision to include changes in practice (such as making a referral to new or existing programs) and policies (such as adopting a new sexuality education curriculum). Additional examples of community change documented in this study include establishing an after school program (modifying a program), extending clinic hours to provide greater access to health services (policy change), and involving health department nurses in school health presentations (new practice).

Local Initiative staff recorded community changes on monthly logs that were sent to evaluators. Evaluators coded (using standard definitions and scoring instructions) and summarized the data and shared graphic presentations and summaries with initiative staff regularly. Prior reports of this document and evaluation system have appeared in research articles ${ }^{7,12}$ and on the Community Tool Box (http://ctb.ukans.edu/). ${ }^{13}$

In this manuscript, community changes were also coded in accordance with the working hypothesis to analyze their potential contribution to more distant population-level health outcomes. Each community change was coded by: the number of community changes in each target area (place or locale), the specific risk/protective factor addressed (related to adolescent pregnancy), the behavior change strategy used, the program component addressed, the sector and target of the change, and the intended duration of the change. Table 1 provides brief definitions developed for each of the categories. Evaluators coded each community change using definitions and coding instructions. Kappa reliability was used to determine interobserver agreement between two University observers. Interobserver agreement was $85 \%$ over all categories.

Some example community changes and their resulting codes may help illustrate the measurement 
system. For instance, one community change involved the local health department increasing accessibility of health services for young people. This change was coded as taking place in the health sector (exposure through sectors), addressing the health services component (intensity), targeting community leaders (exposure to target), addressing the risk factor of contraceptive access (intensity), using the strategy of modifying access (intensity) and was intended to be ongoing (duration). This change also took place in Target Area A (exposure to place). Another community change involved the adoption of human sexuality educational materials for $7^{\text {th }}$ and $8^{\text {th }}$ grade classes. This change was coded as taking place in the school sector, addressing the sexuality education component, targeting youth, addressing the knowledge and skills risk factor, using the strategy of providing information, and was intended to be ongoing. This change also reached Target Areas A and B in addition to other zip codes throughout Wichita.

Insert Table 1 About Here

To explore the working hypothesis about the conditions under which community change might be associated with population-level health outcomes, measures of community change were compared to changes in community-level health indicators associated with adolescent pregnancy. Specifically, the birth rate among females aged 14 to 17 years (number of live births, fetal deaths, divided by the total number of females aged 14 - 17) was the community-level (or population-level) health indicator used in this analysis. Birth rates (as opposed to pregnancy rates) were used because abortion estimates (included in a pregnancy rate) are not available at the zip code level. The state health department provided the data. Data for the 1417 year olds were summarized for this analysis since this group was the primary target group for the Initiative. Changes in the average annual birth rate from a preintervention period (1991 - 1993) were compared to an intervention period (1994-1998). Average birth rates over multiple years were computed since annual birth rates can be influenced by random variation and can fluctuate from year to year. A zstatistic was calculated to assess the statistical significance. More detailed descriptions of the analyses are provided elsewhere. ${ }^{7}$

\section{Results}

This section describes the distribution of community changes across the dimensions of the 
working hypothesis - amount, intensity, duration, and exposure. The results are summarized by locale or place of change (Target Area A and B) along the other dimensions of the hypothesis.

What was the amount of community change?

The Wichita site accomplished 131 changes (the actual number of changes was 139 but 8 changes were not able to be coded across the dimensions of the working hypothesis due to missing information) during the grant period, an average of 2.9 per month or 41 per year. As shown in Table 2, the majority of the community changes (59\%) occurred in Target Area A with 11\% reaching Target Area B and several changes reaching both Target Areas A and B or several other zip codes areas (multiple areas). The amount of community change may differ as the initiative evolves over time. For example, more community changes tended to occur during special events weeks such as Teen Pregnancy Prevention Month, spring break or holidays to provide activities for young people.

Insert Table 2 About Here

What was the intensity of community change?

Community change was also examined by analyzing the distribution of community changes by component, risk factor, and behavior change strategy. These categories were chosen to help reflect the intensity of the community change. That is, were model program components adequately addressed, were key risk factors targeted and were significant behavior change strategies used. Data are described below and shown in Table 2.

Component. Since the site was replicating a model originally tested in South Carolina, we analyzed the distribution of community changes by program component. The model consisted of 6 main components: community alliances, sexuality education, health services, mass media, peer support and education, and alternative activities and life options. ${ }^{6,8}$ Overall, the Wichita site implemented community changes for all model components with some variability in focus across target areas. The community changes tended to primarily address the alternative activities (29\%), sexuality education (19\%), and peer support (19\%) components, with the fewest changes targeting the health services $(6 \%)$ and mass media (1\%) components. The health services component was primarily addressed within Target Area A. 
Risk Factor. The risk/protective factors used in this analysis were knowledge and skills, contraceptive access, unsupervised activities, life options, school performance, and peer support. The greatest number of community changes addressed knowledge and skills ( $43 \%$ for Wichita overall and $43 \%$ for Target Area A). A few changes also addressed life options and opportunities (10\%), unsupervised activities (8\%), and contraceptive access (4\%). Community changes within Target Area A addressed all of the risk factors; community changes in Target Area B addressed several.

Behavior Change Strategy. The behavior change strategies used in this analysis included providing information and skills building, facilitating support (such as creating opportunities to support people or participate in activities, making referrals to services, mentoring or advocacy), providing incentives, changing the physical design of the environment, and modifying access. Target areas A and B primarily used providing information (39\% in Target Area A; $21 \%$ in Target Area B) and facilitating support (34\% in Target Area A; $71 \%$ in Target Area B). Target Area A also used modifying access (5\%) and physical design (3\%) strategies primarily involving referrals for services and creating a safe haven for young people. Several changes occurring within Target Area A also used the strategy of providing incentives $(13 \%)$ such as securing reduced rates for youth activities or donated space and refreshments to make youth participation in activities more likely.

What was the (intended) duration of community change?

Intended duration was measured using three categories: the event occurred only once (e.g., a one-day health fair), the event occurred more than once but was not ongoing (e.g., a graduate education course for teachers), and ongoing (e.g., a policy change to extend clinic hours). The majority (56\%) of the community changes facilitated by the Wichita site were intended to remain ongoing, while $18 \%$ were to occur more than once and $26 \%$ one time only. These findings were similar for Target Area A. For Target Area B, 79\% of the community changes were intended to be ongoing.

What was the exposure through sectors to targets and places?

Data on community changes by sector (i.e., business, health, schools/education, religious, social service/youth organizations, government/law, community, media, family), target (i.e., youth, parents, families, community leaders, general community), and locale (i.e., zip code) were used to examine the exposure to initiative facilitated community changes. Data for sector and target are described below. 
Sector. Forty percent of the community changes took pace in the schools/education sector with $20 \%$ in the social services and youth organizations sector, and $15 \%$ in the general community sector. Community changes taking place in Target Area A involved all of the sectors. Target Area B had the most limited reach with all of the changes focused on the school sector.

Target of Change. The targets of change were primarily community leaders (41\%) and youth (39\%). Target Area A also reached parents (4\%), families (10\%) and the general community (4\%). Link with Population-level Health Outcomes

To further explore the hypothesis we tracked the average birth rate for females aged 14 to 17 years in Wichita target areas for the time periods of preintervention (1991-1993) and intervention (19941998). Figure 1 displays changes in birth rates in Wichita Target Areas A and B and respective comparison areas. We found decreases in birth rates in Target Area A and increases in Target Area B. Closer analysis of the annual birth rates also shows a decreasing trend during the intervention period when compared to the preintervention period for Target Area A and not Target Area B. As reported in the section above, the majority of the changes (59\%) took place in Target Area A, where the lead agency was housed. The effort was also more comprehensive in terms of attention to program component and risk factor, and distribution by sector and target in Target Area A as opposed to Target Area B. These findings suggest a possible link between improvement in the population-level health outcome of birth rate and the amount, intensity and exposure to community change by place.

\section{Insert Figure 1 About Here}

\section{Discussion}

This paper described an analysis of the contribution of community changes facilitated by a multicomponent school and community initiative for the prevention of adolescent pregnancy to the populationlevel health outcome of birth rate. This analysis helped to further our understanding about the conditions under which community change may be related to improvement in more distant health outcomes. The amount and attributes of community changes in Target Area A where decreased birth rates were found were different from the community changes in Target Area B where increases in birth rates were found. 
Positive changes in birth rates were found in the area with the greatest number of community changes and with the most varied distributions of community change across program component, risk factor, behavior change strategy, and sector. These findings help inform the conditions in which community change may be associated with improvements in population level health outcomes.

This analysis of contribution also raises many questions about the link between community change (and multi-faceted community interventions) and health outcome. For example, what is the optimal distribution of community change across all the dimensions of this hypothesis? Would a more equally distributed effort across the different categories in a given community result in larger improvements in population-level health outcomes, or are a relatively small amount of very intense community changes enough to facilitate improvements in health outcomes? For example, a few key community changes that address contraceptive access may be all that is needed, while ongoing attention is given to sexuality education. Although this analysis helps to address these questions, additional research is needed to further explore the possible link between community change (an intermediate outcome) and (more distant) population-level health outcome.

This analysis also has a number of limitations. First, the primary data of community change are selfreported by site staff. For the secondary analysis of contribution, the specific wording of the community change, and what point in time it was reported, influenced how it was coded. This occurred most often with the "target of change" category. For example, a community change involving approval to implement a modified sexuality curriculum that was reported after meeting with the school board would be coded differently than if it was reported after implementation of the curriculum was taking place. The first entry would be coded as targeting community leaders while the second entry would be coded as targeting youth. Second, although the improvements in birth rates are encouraging, one would not expect large changes in health outcome after only a four- to five-year period with approximately 3 years of active implementation. Additional limitations of these data are described elsewhere. ${ }^{7}$ Third, since there is a significant lag in time between the implementation of community interventions (or community changes) and changes in population-level health outcome, it is very difficult to make assumptions about what combinations of changes occurring at a particular time may have contributed to the changes in this population-level health outcome. Additionally, single-year birth rates can fluctuate from year to year making determinations about 
impact more difficult. Finally, in this case study design, events external to the efforts of the community initiatives may also have contributed to changes in health outcome.

Comprehensive and community-controlled initiatives, such as this school-community effort, might be seen as a complex adaptive system. ${ }^{14,15}$ With complex systems, the independent variable (combination of environmental changes) unfolds over time in a dynamic relationship with the local context. In such dynamic contexts, the proper goal is to understand the contribution of local efforts, not the attribution of observed effects to causes (properly beyond the control of outside experimenters).

\section{Implications for Practice}

A number of recommendations flow from this analysis. First, ongoing information on the contribution of local efforts (e.g., community changes) can reflect the theory of change and categories of interest for initiative partners. For example, information on the distribution of community change by risk/protective factors, behavior change strategy, and sectors allows for early and optimal decisions about how staff and volunteers spend their time. Second, future research should analyze the optimal distribution of community changes across these categories of contribution. For example, we might address such questions as how many community changes of each type are needed and how long each change should be in place in order to most effectively improve population-level health outcomes. Third, since comprehensive approaches are more likely to address complex and multi-dimensional (so-called "wicked") health concerns such as adolescent pregnancy, community initiatives should consider facilitating community change across the varied dimensions of the working hypothesis outlined in this manuscript. Finally, this approach offers community initiatives a way to develop empirical legitimacy for their efforts by showing a beginning link between the environmental change they facilitate (an intermediate outcome) and improvement in (more distant) population-level health outcomes.

Although there is still a great deal to be learned about the link between intermediate markers and more distant health outcomes, these findings provide an empirical strategy for exploring this relationship. Data in this analysis of contribution may provide funders, community leaders, and support organizations with information about the conditions under which environmental changes may yield population-level health improvement. Such analyses may help us better understand what is necessary and sufficient for the work of public health improvement. 


\section{Acknowledgements}

We thank the staff, partners and many volunteers of the School/Community Sexual Risk

Reduction Initiative in Kansas and South Carolina, Dr. Murray Vincent from the University of South Carolina, the members of the Technical Review Committee, and Mary K. Campuzano and Carolyn Williams from the Kansas Health Foundation (a philanthropic organization whose mission is to improve the health of Kansans) for making this work possible. Finally, we thank Stergios Tsai Russos and Renee' Boothroyd for their thoughtful feedback and Kim Leach for assistance with final manuscript preparations. 


\section{References}

1. Fawcett, S. B., Paine-Andrews, A., Francisco, V. T., Schultz, J., Richter, K. P., Berkley-Patton, J., Fisher, J. L., Lewis, R. K., Lopez, C. M., Russos, S., Williams, E., Harris, K. J., \& Evensen, P. (in press). Evaluating community initiatives for health and development. In I. Rootman, D. McQueen et al. (Eds.) Evaluating Health Promotion Approaches. Copenhagen, Denmark: Work Health Organization -- Europe.

2. Fawcett, S. B., Francisco, V. T., Hyra, D., Paine-Andrews, A., Schultz, J., Russos, S., Fisher, J., Evensen, P. (2000). Building Healthy Communities. In A.R. Tarlov \& R.F. St.Peter (Eds.) The Society and Population Health Reader: A State and Community Perspective, pp 75-93. New York: The New Press.

3. Himmelman, A.T. (1992). Communities Working Collaboratively for a Change. Humphrey Institute for Public Affairs, University of Minnesota, Minneapolis, 74 pp.

4. Kreuter, M.W., Lezin, N.A., \& Young, L.A. (2000). Evaluation community-based collaborative mechanisms: Implications for practitioners. Health Promotion Practice, 1(1), 49-63.

5. Roussos, S.T. \& Fawcett, S.B. (2000). A review of collaborative partnerships as a strategy for improving community health. Annual Review of Public Health, 21, 369-402.

6. Paine-Andrews, A., Vincent, M. L., Fawcett, S. B., Campuzano, M. K., Harris, K., Lewis, R., Williams, E., \& Fisher, J. (1996). Replicating a Community-based Initiative for the Prevention of Adolescent Pregnancy: From South Carolina to Kansas. Family and Community Health, 19(1), 14-30.

7. Paine-Andrews, A., Harris, K.J., Fisher, J.L., Lewis, R.K., Williams, E.L., Fawcett, S.B., \& Vincent, M.L. (1999). Effects of a Replication of a School/Community Model for Preventing Adolescent Pregnancy in three Kansas Communities. Family Planning Perspectives, 31(4), 182-189. 
8. Vincent, M.L., Clearie, A., \& Schluchter, M. (1987). Reducing adolescent pregnancy through school and community-based education. Journal of the American Medical Association, 257(24), 3382-3386.

9. Koo, H. et al. (1994). Reducing adolescent pregnancy through a school and community-based intervention: Denmark, South Carolina, revisited. Family Planning Perspectives, 26(5), 206-211.

10. Francisco, V.T., Paine, A.L., \& Fawcett, S. B. (1993). A methodology for monitoring and evaluating community health coalitions. Health Education Research: Theory and Practice, $\underline{8}(3), 403-416$.

11. Fawcett, S. B., Francisco, V. T., Paine-Andrews, A., Lewis, R. K., Richter, K. P., Harris, K. J., Williams, E. L., Berkley, J. Y., Schultz, J. A., Fisher, J. L., \& Lopez, C. M. (1994). Work Group Evaluation Handbook: Evaluating and supporting community initiatives for health and development. Work Group on Health Promotion and Community Development, University of Kansas: Lawrence, KS.

12. Lewis, R. K., Paine-Andrews, A., Fisher, J. L., Custard, C., Fleming-Randle, M., \& Fawcett, S. B. (1999). Reducing the risk for adolescent pregnancy: Evaluation of a school/community partnership in a military community. Family and Community Health, 22(2), 16-30.

13. Fawcett, S. B., Francisco, V. T., Schultz, J. A., Berkowitz, B., Wolff, T. J., \& Nagy, G. (2000). The Community Tool Box: A Web-Based Resource for Building Healthier Communities. Public Health Reports, 115, 274-278.

14. Eoyang, G. H. (1997). Coping With Chaos: Seven Simple Tools. Cheyenne, WY: Lagumo Corp.

15. Milstein, R. L. \& Wetterhall, S. F. (1991). Framework for Program Evaluation in Public Health. MMWR, 48: 1-40. 
Table 1. Analysis of Contribution of Community Change to Population-level Health Outcome

\begin{tabular}{|c|c|}
\hline Dimension of the Working Hypothesis & Coding Category \\
\hline $\begin{array}{l}\text { Amount: How much change was } \\
\text { reported? }\end{array}$ & Total number of community changes \\
\hline $\begin{array}{l}\text { Intensity: What components and } \\
\text { risk/protective factors were addressed? } \\
\text { What behavior change strategies were } \\
\text { used? }\end{array}$ & 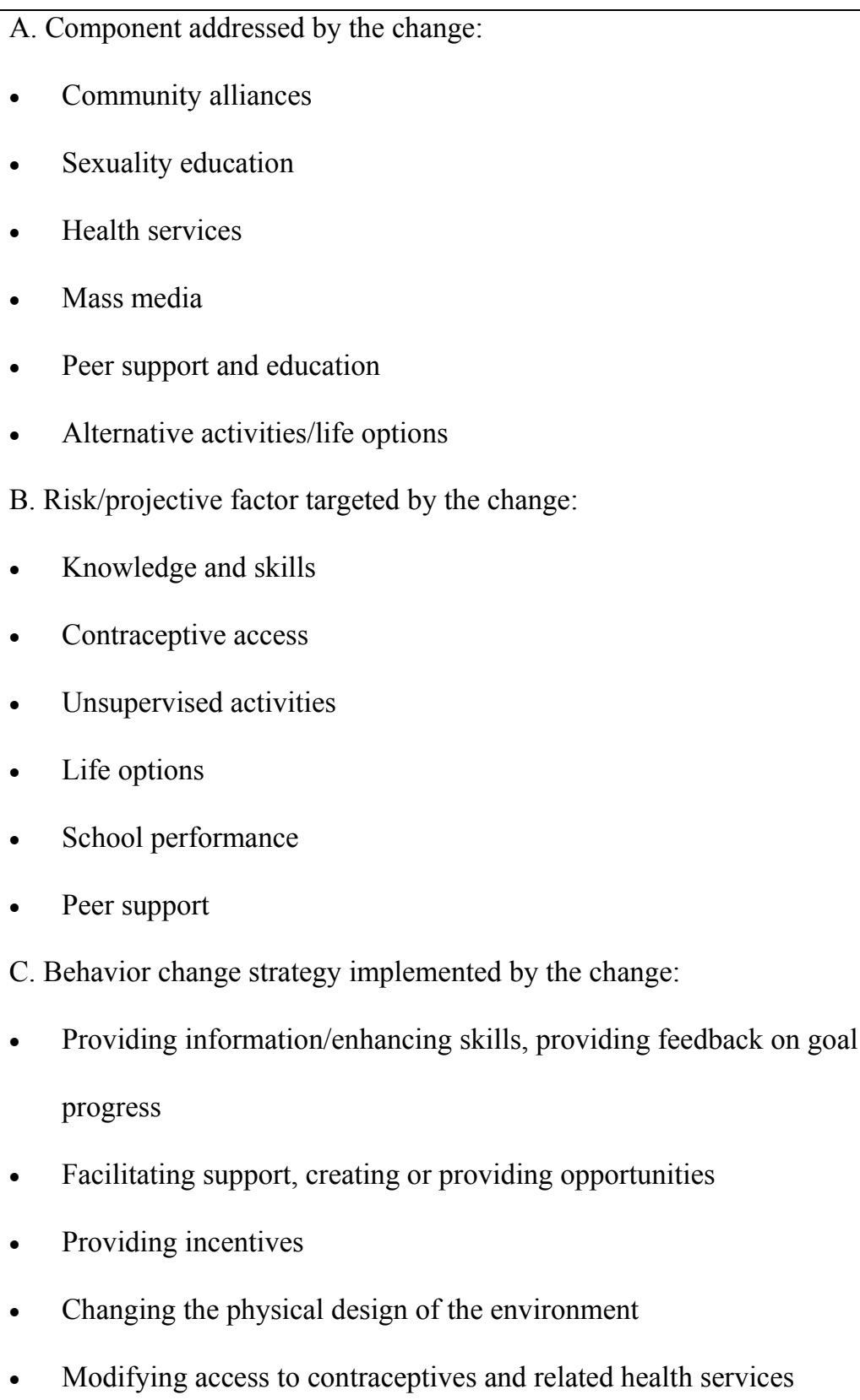 \\
\hline Duration: How long were they in place? & $\begin{array}{l}\text { Intended duration of the change: } \\
\text { - One time event } \\
\text { - More than once, but not ongoing }\end{array}$ \\
\hline
\end{tabular}




\begin{tabular}{|c|c|}
\hline & - $\quad$ Ongoing \\
\hline $\begin{array}{l}\text { Exposure: Were changes distributed } \\
\text { through different sectors of the } \\
\text { community? Were target groups } \\
\text { reached? In what places were the } \\
\text { changes concentrated? }\end{array}$ & $\begin{array}{l}\text { A. Sector where the change took place: } \\
\text { - } \text { Business } \\
\text { - Health } \\
\text { - Schools/Education } \\
\text { - } \text { Religious } \\
\text { - Social services, community \& youth } \\
\text { - Government/law enforcement } \\
\text { - Community } \\
\text { - Media } \\
\text { - Family \& caregiver } \\
\text { B. Target of change: } \\
\text { - Youth } \\
\text { - Parents \& caregivers } \\
\text { - Families } \\
\text { - Community leaders } \\
\text { - General community } \\
\text { C. Location of the community change: } \\
\text { Target Area or zip code }\end{array}$ \\
\hline
\end{tabular}


Table 2. An analysis of the contribution of community changes to a population-level health outcome in Wichita. (Note: "Other" refers to other nearby zip code areas and "Multiple" refers to zip codes in addition to Target Areas A and/or B.

\begin{tabular}{|c|c|c|c|c|c|c|}
\hline & Area A & Area B & A \& B & Other & Multiple & Total \\
\hline Amount of Change & $59 \%(77)$ & $11 \%(14)$ & $5 \%(6)$ & $15 \%(19)$ & $11 \%(15)$ & 131 \\
\hline \multicolumn{7}{|c|}{ What was the Intensity of Change? } \\
\hline \multicolumn{7}{|l|}{ ProgramComponent: } \\
\hline Community Alliances & $9 \%(7)$ & $7 \%(1)$ & $17 \%(1)$ & $21 \%(4)$ & $20 \%(3)$ & $12 \%(16)$ \\
\hline Sexuality Education & $19 \%(15)$ & $14 \%(2)$ & $67 \%(4)$ & $21 \%(4)$ & $20 \%(3)$ & $21 \%(28)$ \\
\hline Health Services & $6 \%(5)$ & 0 & 0 & 0 & $7 \%(1)$ & $5 \%(6)$ \\
\hline Mass Media & $1 \%(1)$ & 0 & 0 & $5 \%(1)$ & $33 \%(5)$ & $5 \%(7)$ \\
\hline Peer Support & $19 \%(15)$ & $21 \%(3)$ & $17 \%(1)$ & $37 \%(7)$ & $13 \%(2)$ & $21 \%(28)$ \\
\hline Alternative Activities & $29 \%(22)$ & $29 \%(4)$ & 0 & $5 \%(1)$ & 0 & $21 \%(27)$ \\
\hline Other & $16 \%(12)$ & $29 \%(4)$ & 0 & $11 \%(2)$ & $7 \%(1)$ & $15 \%(19)$ \\
\hline \multicolumn{7}{|l|}{ Risk Factors: } \\
\hline Knowledge \& Skills & $43 \%(33)$ & $14 \%(2)$ & $67 \%(4)$ & $42 \%(8)$ & $60 \%(9)$ & $43 \%(56)$ \\
\hline Contraceptive Access & $5 \%(4)$ & 0 & 0 & 0 & $7 \%(1)$ & $4 \%(5)$ \\
\hline Unsup. Activities & $10 \%(8)$ & $14 \%(2)$ & 0 & 0 & 0 & $8 \%(10)$ \\
\hline Life Options/Opport. & $12 \%(9)$ & $14 \%(2)$ & 0 & $11 \%(2)$ & 0 & $10 \%(13)$ \\
\hline School Performance & $1 \%(1)$ & 0 & 0 & 0 & $7 \%(1)$ & $2 \%(2)$ \\
\hline Peer Support & $10 \%(8)$ & $14 \%(2)$ & 0 & $21 \%(4)$ & 0 & $11 \%(14)$ \\
\hline Other & $18 \%(14)$ & $43 \%(6)$ & $33 \%(2)$ & $26 \%(5)$ & $27 \%(4)$ & $24 \%(31)$ \\
\hline \multicolumn{7}{|l|}{ Change Strategy: } \\
\hline Providing Information & $39 \%(30)$ & $21 \%(3)$ & $83 \%(5)$ & $42 \%(8)$ & $53 \%(8)$ & $41 \%(54)$ \\
\hline Facilitating Support & $34 \%(26)$ & $71 \%(10)$ & $17 \%(1)$ & $53 \%(10)$ & $27 \%$ & $39 \%(51)$ \\
\hline Incentives & $13 \%(10)$ & $7 \%(1)$ & 0 & $5 \%(1)$ & 0 & $9 \%(12)$ \\
\hline Physical Design & $3 \%(2)$ & 0 & 0 & 0 & 0 & $2 \%(2)$ \\
\hline
\end{tabular}




\begin{tabular}{|c|c|c|c|c|c|c|}
\hline Modifying Access & $5 \%(4)$ & 0 & 0 & 0 & $7 \%(1)$ & $4 \%(5)$ \\
\hline Other & $6 \%(5)$ & 0 & 0 & 0 & $13 \%(2)$ & $5 \%(7)$ \\
\hline \multicolumn{7}{|c|}{ What was the (Intended) Duration of Community Change? } \\
\hline One time & $28 \%(22)$ & $21 \%(3)$ & $17 \%(1)$ & $37 \%(7)$ & $7 \%(1)$ & $26 \%(34)$ \\
\hline More than once & $17 \%(13)$ & 0 & $33 \%(2)$ & $11 \%(2)$ & $40 \%(6)$ & $18 \%(23)$ \\
\hline Ongoing & $55 \%(42)$ & $79 \%(11)$ & $50 \%(3)$ & $53 \%(10)$ & $53 \%(8)$ & $56 \%(74)$ \\
\hline Other & 0 & 0 & 0 & 0 & 0 & 0 \\
\hline \multicolumn{7}{|c|}{ What was the Exposure to Community Change? } \\
\hline \multicolumn{7}{|l|}{ Sector: } \\
\hline Business & $6 \%(5)$ & 0 & 0 & 0 & $7 \%(1)$ & $5 \%(6)$ \\
\hline Health & $8 \%(6)$ & 0 & 0 & $5 \%(1)$ & $7 \%(1)$ & $6 \%(8)$ \\
\hline Schools/Education & $36 \%(28)$ & $100 \%(14$ & $67 \%(4)$ & $16 \%(3)$ & $20 \%(3)$ & $40 \%(52)$ \\
\hline Religious & $4 \%(3)$ & 0 & 0 & $5 \%(1)$ & $7 \%(1)$ & $4 \%(5)$ \\
\hline Social Services/Youth & $21 \%(16)$ & 0 & 0 & $42 \%(8)$ & $13 \%(2)$ & $20 \%(26)$ \\
\hline Government/Law & $4 \%(3)$ & 0 & 0 & $5 \%(1)$ & $27 \%(4)$ & $6 \%(8)$ \\
\hline Community & $16 \%(12)$ & 0 & $33 \%(2)$ & $21 \%(4)$ & $13 \%(2)$ & $15 \%(20)$ \\
\hline Media & $1 \%(1)$ & 0 & 0 & 0 & $7 \%(1)$ & $2 \%(2)$ \\
\hline Family & $4 \%(3)$ & 0 & 0 & $5 \%(1)$ & 0 & $3 \%(4)$ \\
\hline Other & 0 & 0 & 0 & 0 & 0 & 0 \\
\hline \multicolumn{7}{|l|}{ Target of Change: } \\
\hline Youth & $43 \%(33)$ & $50 \%(7)$ & $50 \%(3)$ & $32 \%(6)$ & $13 \%(2)$ & $39 \%(51)$ \\
\hline Parents & $4 \%(3)$ & 0 & 0 & 0 & 0 & $2 \%(3)$ \\
\hline Families & $10 \%(8)$ & 0 & 0 & $16 \%(3)$ & $7 \%(1)$ & $9 \%(12)$ \\
\hline Community Leaders & $39 \%(30)$ & $50 \%(7)$ & $50 \%(3)$ & $42 \%(8)$ & $40 \%(6)$ & $41 \%(54)$ \\
\hline General Community & $4 \%(3)$ & 0 & 0 & $11 \%(2)$ & $40 \%(6)$ & $8 \%(11)$ \\
\hline Other & 0 & 0 & 0 & 0 & 0 & 0 \\
\hline
\end{tabular}


Target Area A

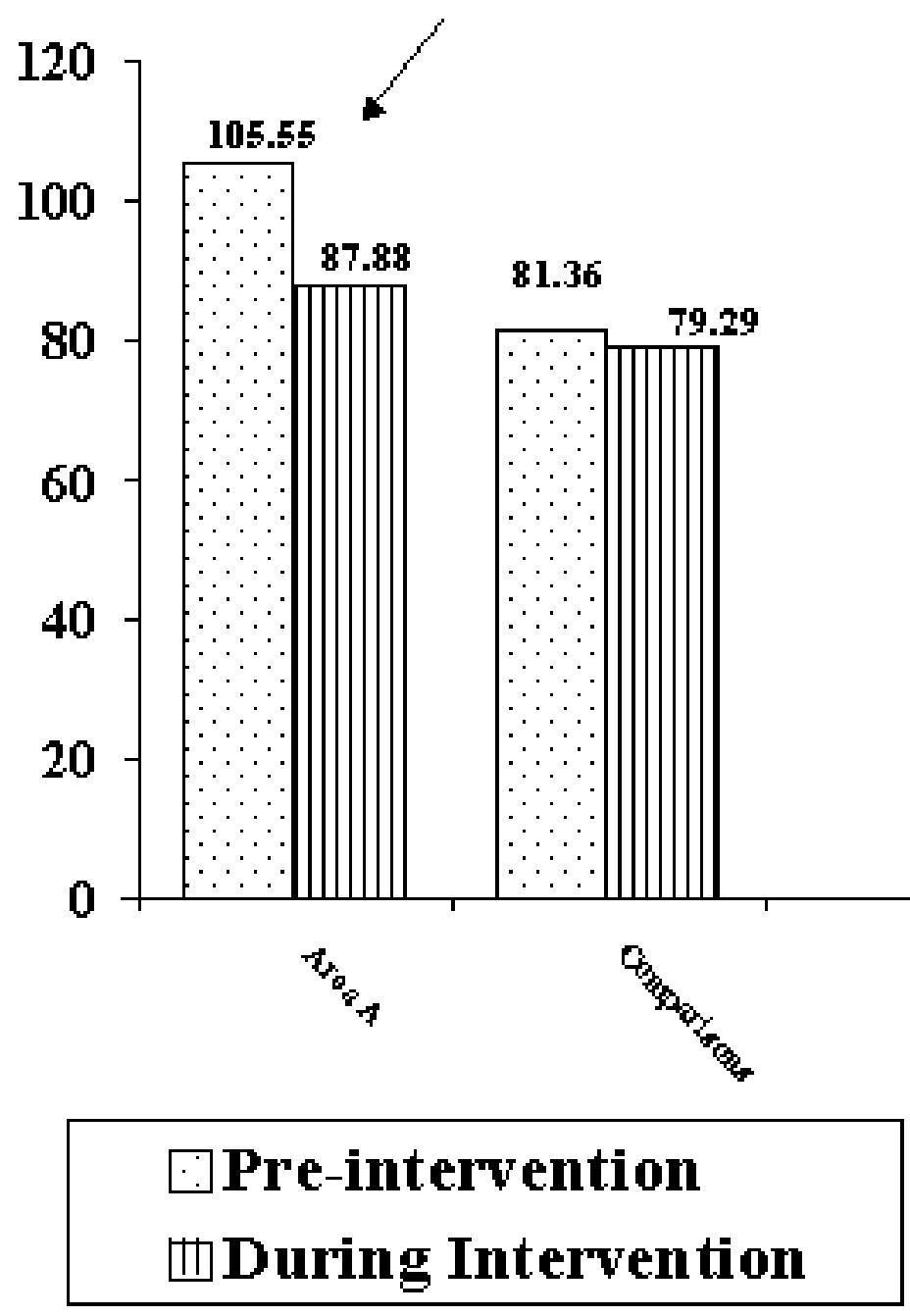

Target Area B

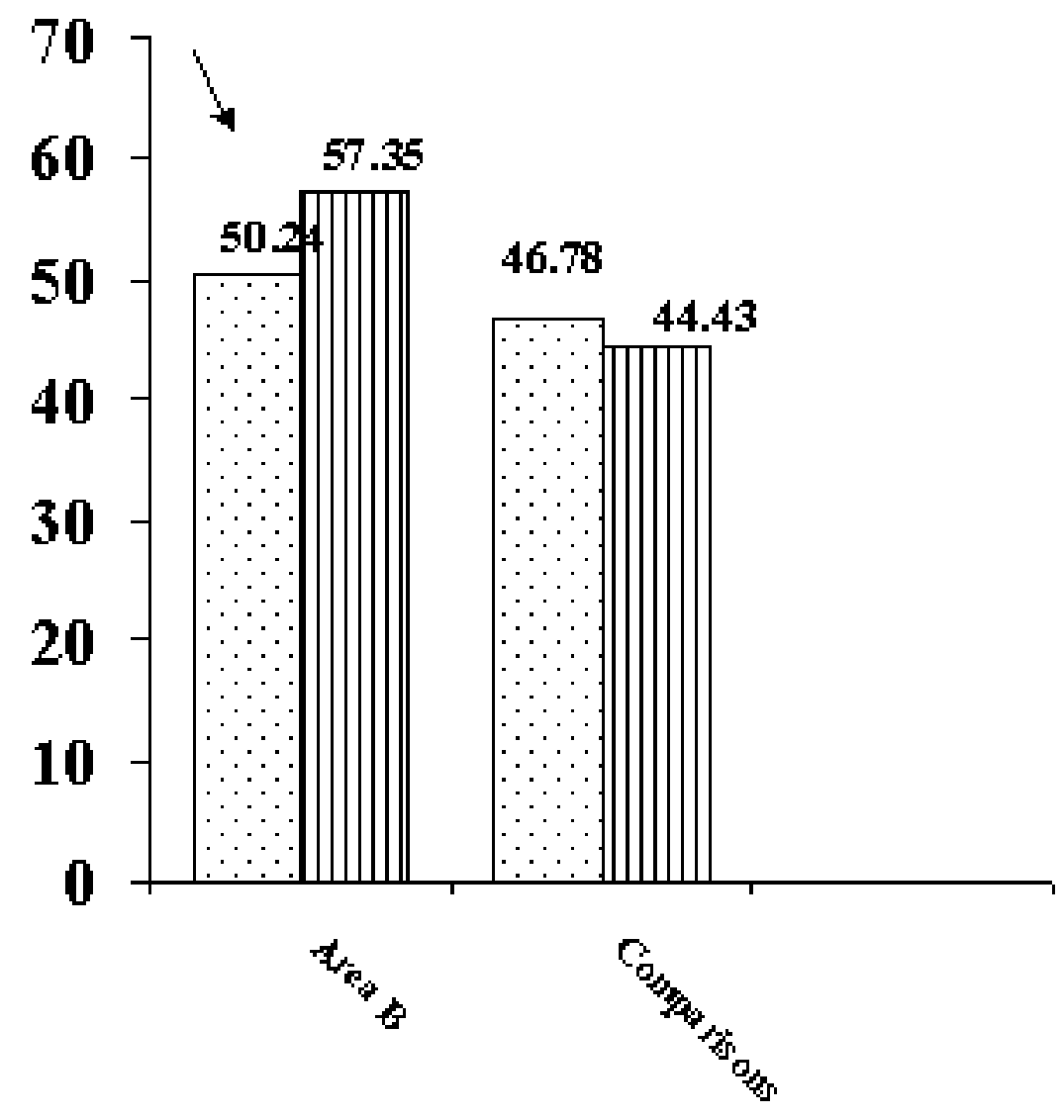

Pre-intervention

四During Intervention 